\title{
The Impact of Recombinant Human Erythropoietin Treatment on Motor Impairment in Rotenone-Induced Parkinsonism in Rats
}

\author{
Dalia M. Abd-Elhalim", Mona A. Hussain ${ }^{2 *}$, Mohamed Abdo ${ }^{1}$ \\ Departments of ${ }^{1}$ Medical Physiology, Faculty of Medicine, Suez Canal University, and ${ }^{2}$ Medical Physiology. Faculty \\ of Medicine, Port Said University, Egypt
}

\begin{abstract}
Background: Parkinson's disease is a neurodegenerative disease mainly characterized by loss of dopaminergic neurons in the substantia nigra pars compacta and their terminals in the striatum. The development of neuroprotective drugs that slow or delay neurodegeneration became of a considerable interest. In numerous animal models, exogenously administered EPO exhibits neuroprotective effects. Aim: The current research investigated the impact of administration of recombinant human EPO (rhEPO) in rotenone parkinsonian rats. Materials and Methods: Thirty two adult male albino Sprague-Dawly rats were equally and randomly divided into four groups; group 1 the vehicle-treated group, group 2 rotenone-treated group, group 3 treated with rotenone in addition to intranasal rhEPO and group 4 treated with rotenone in addition to intraperitoneal rhEPO. The motor performance of the rats was evaluated. Malondialdehyde and reduced glutathione were assayed. Blood indices were measured. Histopathology of the substantia nigra was also done. Results: Results showed that rotenone-treated rats exhibited significant impairment of motor coordination and marked degeneration of substantia nigra neurons was observed. Both intranasal and intraperitoneal rhEPO treatment improved the motor deficit and significantly increased the number of neurons in the SNpc. intraperitoneal rhEPO significantly increased lipid peroxide and significantly affected blood indices. Conclusion: Our findings suggest that, EPO may have neuroprotective effect in PD. Systemic rhEPO neuroprotective effects may be attenuated by its adverse effects such as increase of OS in the vascular system and stimulation of erythropoiesis. Small doses of intranasal EPO may be sufficient to produce neuroprotection without affecting erythropoiesis and further researches are required to address the mechanisms of neuroprotective effects of EPO.
\end{abstract}

Keywords: neuroprotection; oxidative stress; neurodegeneration

\section{Introduction}

Parkinson's disease (PD) is a neurodegenerative disease. It is characterized clinically by motor complications (asymmetric onset of bradykinesia, rigidity, resting tremor), and non-motor complications (depression, sleep disturbances, memory deficits). These complications are mainly the outcome of neurodegeneration of the substantia nigra pars compacta (SNpc), which leads to subsequent reduction of dopaminergic input

*Corresponding author: monazoozdr@yahoo.com 
to the striatum ${ }^{(1)}$. Although the pathogenesis of PD is not completely understood, reactive oxygen species (ROS) over-generation, oxidative stress and mitochondria dysfunction are well recognized in the pathogenesis of $\mathrm{PD}^{(2,3)}$. Rotenone induces systemic inhibition of mitochondrial complex I and cause selective nigrostriatal dopaminergic degeneration ${ }^{(4)}$. The dopaminergic neurodegeneration caused by rotenone is mediated through contribution of reactive oxygen species (ROS), specifically nitric oxide (NO) and hydroxyl radicals $(\cdot \mathrm{OH})^{(5)}$. Erythropoietin (EPO) is a cytokine that acts on erythroid progenitor proliferation and differentiation. It has been reported that, EPO might have a direct protective role against a variety of neurotoxic insults, such as free radical injury ${ }^{(6)}$, and exposure to neurotoxic agent ${ }^{(7,8)}$. EPO has been shown to have beneficial effects against oxidative stress $^{(9)}$, and inflammation ${ }^{(10,11)}$. In the brain, EPO increases in response to oxidative or nitrosative stress ${ }^{(12)}$. Protection against oxidative stress by EPO involves preventing excitotoxicity ${ }^{(10,13)}$ and free radical exposure ${ }^{(14,15)}$. Recombinant human EPO (rhEPO) was proved to have neuroprotective effects in several models of nervous tissue damage ${ }^{(16,17)}$. A study in Parkinson's disease patients using rhEPO produced in Cuba (ior-EPOCIM) found that, (ior-EPOCIM) was safe and the preliminary positive responses in motor, cognitive and affective domains that were observed could suggest its potential effectiveness as a treatment for $\mathrm{PD}^{(18)}$. An exploratory pilot study investigated the effects of (rhEPO) on motor and non-motor symptoms (NMS) in PD patients. It found that rhEPO had beneficial effects on NMS but not on motor function $^{(19)}$. Nasal drug delivery has major advantages including direct transport of absorbed drug into systemic circulation and bypassing first-pass effect of liver and gastrointestinal tract so that dose can be minimized, bypassing the blood brain barrier, providing an alternative to invasive methods of drug administration, lower enzymatic activity when compared with gastrointestinal tract and liver, avoidance of gastrointestinal membrane irritation, reduced risk of overdose and infection, selfmedication and ease of convenience that increases patients' compliance. Recently, several studies confirmed the delivery of EPO to the brain via the nasal route by avoiding the blood brain barrier, and reported that this pathway could be safer and 10 times faster than the intravenous route $^{(20)}$. Taken together, these results offered an interesting perspective to our research, which aimed to investigate the neuroprotective effects of rhEPO on rotenone-induced Parkinsonism in rat.

\section{Materials and Methods}

This study was performed at the Physiology Department, Faculty of Medicine, Suez Canal University, Ismailia, Egypt.

\section{Animals}

Thirty-two adult male albino SpragueDawly rats (body weight $120-180 \mathrm{gm}$ ) purchased from center for experimental animals, Faculty of Veterinarian Medicine, Zagazig University were used in the study. All rats were left to acclimatize for one week prior to the experiment and were housed in plastic cages maintained at controlled room temperature (22-24 C) with 12hour diurnal (day and night change) with free access to standard pellet animal diet and tap water. The animals were equally and randomly divided into four groups; Group 1: (the vehicle-treated group), group 2: (rotenone-induced parkinsonism without intervention group), group 3: (rotenoneinduced parkinsonism with intranasal recombinant human erythropoietin treatment group), and group 4: (rotenoneinduced parkinsonism with systemic 
(intraperitoneal) recombinant human erythropoietin treatment group).

Induction of experimental parkinsonism:

Rotenone (Sigma-Aldrich, MO, USA) was dissolved in 1:1 (v/v) dimethylsulfoxide (DMSO, Sigma-Aldrich, MO, USA) and polyethylene glycol (PEG-300; Sigma-Aldrich, MO, US). Rats in group 2, 3 and 4 were injected with rotenone $(1.5 \mathrm{mg} / \mathrm{kg}$ subcutaneously) every 48 hours \pm 2 hours. Total number of injections was six injections. Group 1 received six subcutaneous injections of the vehicle (1:1, DMSO/PEG-300) with the same schedule as other groups ${ }^{(21)}$.

Treatment with recombinant human erythropoietin (rhEPO):

In group 3, $2.4 \mathrm{IU} /$ rat of rhEPO (EPICO, Egypt) were administered intranasal (22). While, in group 4, rhEPO (EPICO, Egypt) was injected intraperitoneally (5000 IU/kg) 30 minutes before each rotenone injection.

\section{Functional assessment:}

Twenty four hours after the last injection of rotenone (day 12), rats were screened for motor impairments using the open-field test and rota-rod test.

\section{A- Open field test:}

Assessment was done in the open field apparatus which consists of a rectangular box arena with the measurements 115 X 115 X 44 $\mathrm{cm}$. The arena floor is painted with dark lines that form a $5 \times 5 \mathrm{~cm}$ rectangular unit's pattern ${ }^{(23)}$. Rats were introduced individually into the center of the open field arena and behavioral parameters were observed for 5 minutes, the observer recorded ambulation frequency (the number of squares crossed), number of stops and the vertical movement (rearing frequency). Furthermore, activity index (the number of squares passed in a locomoting interval =total number of squares divided by the total number of stops) was calculated for each rat ${ }^{(21)}$.

\section{B- Rota-rod test:}

To assess balance and motor coordination, each rat was placed on a rotating rod (10 cm long and $4 \mathrm{~cm}$ in diameter). The rod rotation speed was $20 \mathrm{rpm}$. Each rat was left on the rotating rod and the time spent from putting the animal on the shaft of the rotarod, till it falls to the ground (latency) was recorded. The maximal time that was allowed for each rat was 5 minutes ${ }^{(24)}$.

\section{Measurement of blood indices:}

After functional assessment, rats were anesthetized and one milliliter of blood was withdrawn from retro-orbital venous plexus from each rat into an EDETAcontaining eppendorfs and the following tests were performed: hemoglobin concentration, hematocrit, total erythrocyte count, mean cell volume, mean cell hemoglobin and mean cell hemoglobin concentration. Blood testing was carried out using the hematology autoanalyzer.

\section{Processing of the brains}

Anesthetized rats were killed by decapitation. Brains were quickly dissected and washed with ice-cold saline. Two brains from each group were fixed using 4\% paraformaldehyde and then embedded with paraffin. $4 \mu \mathrm{m}$ thicknesses sections were prepared from each paraffin block for histopathological staining with hematoxylin \& eosin (H \& E) and cresyl violet for Nissl-staining. The remaining brains in each group were homogenized in Tris buffer (10 $\mathrm{mM}$ Tris $\mathrm{HCl}, 1 \mathrm{mM}$ EDTA, $0.32 \mathrm{M}$ sucrose, $\mathrm{pH}=7.8)$ as $10 \%(\mathrm{w} / \mathrm{v})$ using a Teflon homogenizer (Glas Col homogenizer system, Vernon hills, USA). The homogenate was sonicated and centrifuged at 20,000 $\mathrm{xg}$ for $10 \mathrm{~min}$, then, supernatant was kept at -80 ${ }^{\circ} \mathrm{C}$ until determination of the biochemical 
markers of oxidative stress (malondialdehyde and glutathione peroxidase) ${ }^{(21)}$.

Determination of lipid peroxides (Malondialdehyde) in brain tissues

Tissue malondialdehyde (MDA) were estimated according to the Spectrophotometric method ${ }^{(25)}$ using lipid peroxides kits (Biodiagnostics, Egypt).

Determination of total glutathione peroxidase (GPX) activity in brain tissues

GPx activity in brain tissues were estimated according to the spectrophotometric method using glutathione peroxidase kits (Biodiagnostics, Egypt).

\section{Statistical analysis}

All the data was expressed as mean \pm standard error of mean (SEM) and analyzed using Statistical Package for Social Sciences (SPSS) program version 20. All the comparisons among groups were carried out using one way Analysis of Variance (ANOVA) followed by Bonferroni post hoc test to test the significance difference among group means. Data were considered statistically significant with $\mathrm{P} \leq 0.05$.

\section{Results}

Functional assessment results:

rhEPO treatment (intranasally and intraperitoneally) partially ameliorated motor impairment in rotenone-induced parkinsonism.

\section{A- Open field results:}

Rotenone injections in group 2 significantly decreased rearing (vertical movement) frequency $(p=0.03)$. Rotenone injections in group 2 decreased the ambulation frequency, number of stops and activity index but this change was not significant ( $p>$ 0.05). rhEPO treatment partially ameliorated this change in groups 3 and 4 with no significant change between group 1 and groups 3 and 4 (table 1). There was no significant difference between group 3 and group 4 (table 1 ).

Table 1: Open field test results in the study groups

\begin{tabular}{|l|ccccc|}
\hline Open field test & $\begin{array}{c}\text { Group 1 } \\
\text { (vehicle- } \\
\text { treated) }\end{array}$ & $\begin{array}{c}\text { Group 2 } \\
\text { (rotenone- } \\
\text { treated) }\end{array}$ & $\begin{array}{c}\text { Group 3 } \\
\text { (rotenone } \\
\text { intranasal } \\
\text { EPO) }\end{array}$ & $\begin{array}{c}\text { Group 4 } \\
\text { (rotenone } \\
\text { i.p EPO) }\end{array}$ & $\begin{array}{c}\text { P } \\
\text { value }\end{array}$ \\
\hline Ambulation frequency & $43 \pm 4.6$ & $26 \pm 5$ & $27 \pm 5$ & $43 \pm 12.5$ & 0.3 \\
Number of stops & $7 \pm 1.5$ & $5.6 \pm 1$ & $4.5 \pm 1$ & $4.5 \pm 0.6$ & 0.4 \\
Activity index & $7 \pm 0.6$ & $4.7 \pm 0.6$ & $6 \pm 1.4$ & $9.8 \pm 3$ & 0.2 \\
Rearing frequency & $5 \pm 1.1$ & $1 \pm 0.4$ & $2 \pm 0.3$ & $2 \pm 0.6$ & 0.025 \\
\hline
\end{tabular}

Data are presented as Mean \pm SEM. * Significant decrease in rearing frequency in group 2 ( rotenone only) vs. group 1 (vehicle-treated) $(p=0.03)$.

\section{B- Rota-rod test results:}

Rotenone injections decreased the latency time in rats in group 2 and this change was significantly different from the latency time in normal rats in group 1, while rhEPO treatment in groups 3 and 4 partially improved this effect and there was no signify cant difference between latency time in group 1 and groups 3 and 4 (figure 1). There was no significant difference between group 3 and group 4 (figure 1).

Oxidative stress parameters results:

A- Lipid peroxide:

Rotenone injections in group 2 increased lipid peroxide level (marker of lipid peroxidation) in brain tissue but this increase was not significantly different from lipid perox- 
ide mean level in group 1. In group 4, lipid peroxide mean level significantly increased than lipid peroxide mean level in group 1 so intraperitoneal rhEPO injections in group 4 caused more increase in lipid peroxide mean level . In group 3, intranasal rhEPO treatment didn't significantly affect the oxidative stress parameters (Table 2).

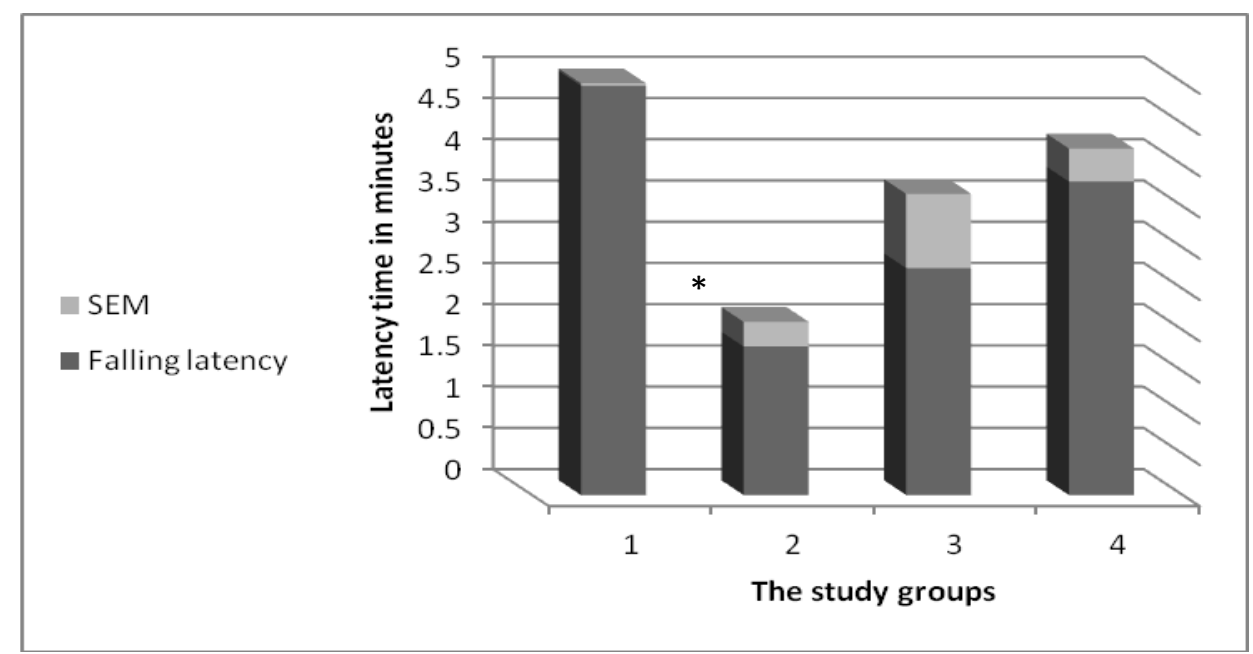

Figure 1: Rota-rod test results in the study groups.

* Significant decrease in latency time in group 2 (rotenone only) vs. group 1 (vehicle-treated) $(p=0.007)$.

\section{B- Glutathione peroxidase:}

There was a trend of decreasing the level of glutathione peroxidase levels (antioxidant activity) in groups 2, 3 and 4 but this difference was statistically not significant $(p=0.07)$ (Table 2). Taken together these results suggested that rotenone alone in group 2 increased the oxidative stress marker and decrease the antioxidant marker but both effects failed to reach a significant level. Intranasal rhEPO had no significant change concerning the oxidative markers in group 3. Systemic rhEPO significantly increased the oxidative stress marker and decreased the antioxidant marker but insignificantly in group 4

Table 2: Comparison of oxidative stress parameters in the study groups

\begin{tabular}{|c|c|c|c|c|c|}
\hline $\begin{array}{l}\text { Oxidative stress } \\
\text { Parameters }\end{array}$ & $\begin{array}{l}\text { Group } 1 \\
\text { (vehicle- } \\
\text { treated) }\end{array}$ & $\begin{array}{l}\text { Group } 2 \\
\text { (rotenone- } \\
\text { treated) }\end{array}$ & $\begin{array}{l}\text { Group } 3 \\
\text { (rotenone } \\
\text { intranasal EPO) }\end{array}$ & $\begin{array}{l}\text { Group } 4 \\
\text { (rotenone + } \\
\text { i.p EPO) }\end{array}$ & $\begin{array}{l}P \\
\text { value }\end{array}$ \\
\hline $\begin{array}{l}\text { Lipid peroxide } \\
\text { (nmol/gram of tissue) }\end{array}$ & $651 \pm 51$ & $785 \pm 52$ & $730 \pm 71$ & ${ }^{* a} 855 \pm 18$ & ${ }^{*} 0.03$ \\
\hline $\begin{array}{l}\text { Glutathione Peroxidase } \\
\text { (U/gram of tissue) }\end{array}$ & $32 \pm 5$ & $26 \pm 11$ & $19 \pm 14.5$ & $5 \pm 2.8$ & 0.07 \\
\hline
\end{tabular}




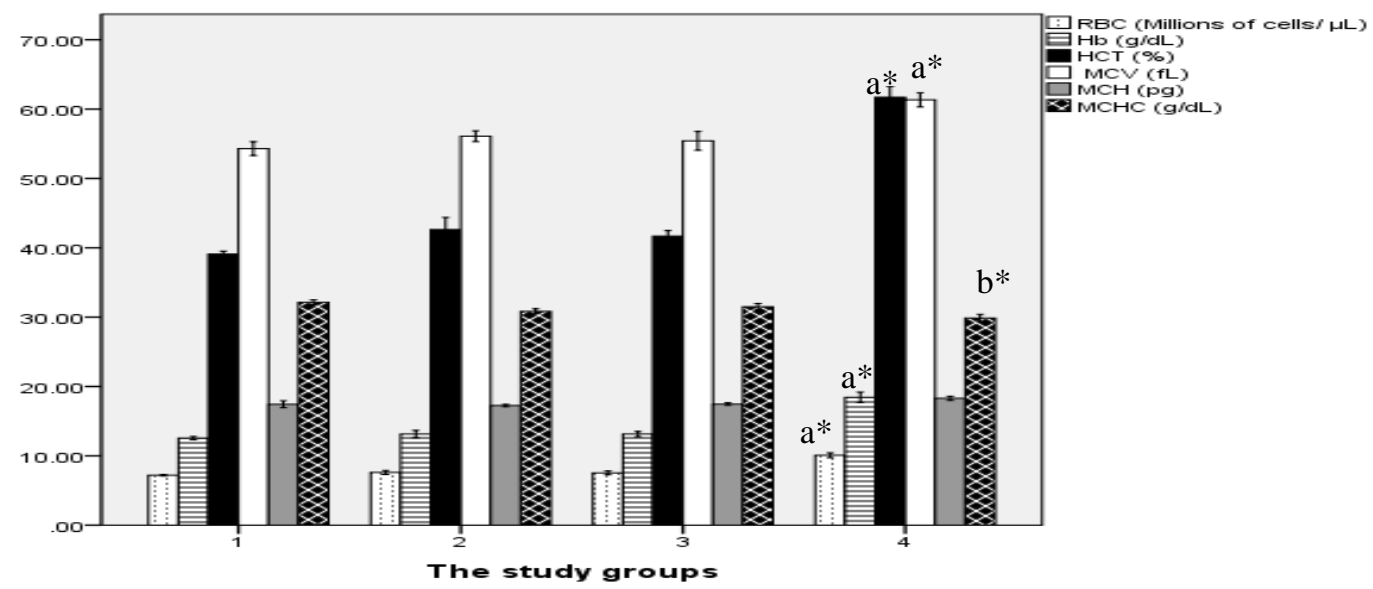

Figure 2: Comparison of means of blood indices in the study groups $a^{*}=$ significant increase in RBC, Hb, HCT and MCV in group 4 (rotenone + i.p rhEPO) vs. groups 1,2 , and $3 ; b^{*}=$ significant decrease in $M C H C$ in group 4 (rotenone + i.p. rhEPO) vs. group 1 (vehicle-treated).

Blood indices results:

Intraperitoneal rhEPO injections of 5000 $\mathrm{IU} / \mathrm{kg}$ significantly increased RBC, $\mathrm{Hb}, \mathrm{HCT}$ and MCV, significantly decreased MCHC and did not affect $\mathrm{MCH}$. Intranasal rhEPO administration of $2.4 \mathrm{IU} / \mathrm{rat}$ had no significant effect on all blood indices (figure 2).

\section{Histopathological results}

Rotenone injections significantly decreased the number of neurons in basal ganglia and rhEPO injections protected basal ganglia neurons against rotenone effect. The number of basal ganglia neurons was significantly decreased in group 2 vs. groups 1,3 and $4(p=0.007, p=0.048$ and $p=0.011$ respectively) (figure 3 ). Histological examination showed that vehicle-treated rats had normal neurons in substantia nigra. Rotenone injections caused marked neuronal degeneration in substantia nigra. Intranasal and systemic rhEPO treatment significantly ameliorated this effect in rats in groups 3 and 4 as compared to group 2 (Figure 4). Nissl bodies staining by cresyl violet stain confirmed the previous results and revealed that vehicle treated rats had a high number of Nissl stained neurons in the substantia nigra, whereas, rotenone treated rats showed a significant marked decrease in the number of Nissl stained neu- rons. Marked improvement was observed with rhEPO administration in groups 3 and 4 (Figure 5).

\section{Discussion}

In this study, rotenone treated animals exhibited significant impairment of motor coordination in the rota-rod test and exhibited motor deficits in the open-field test. However, in the open-field test, the decrease in the rearing frequency was significant. While the decrease in the ambulation frequency, number of stops and activity index did not reach statistical significance. Also, the histopathological analysis in this study showed that, rotenone injection in rats caused marked degeneration of the substantia nigra pars compacta (SNpc) neurons. PD is a neurodegenerative disease mainly characterized by loss of dopaminergic (DA) neurons in the substantia nigra pars compacta (SNpc). Rotenone models for PD appear to mimic most clinical features of idiopathic PD and recapitulate the slow and progressive loss of dopaminergic (DA) neurons ${ }^{(26)}$. Consistently, Morais et al. $2012^{(27)}$ have shown that, short term intraperitoneal rotenone administration caused an important locomotor impairment. Moreover, Fleming et al. $2004^{(28)}$ re- 
ported that rearing was the only test consistently affected by rotenone. Therefore, in our study, the motor impairment came on line with the marked degeneration of the neurons in the SNpc. In the present study, the animals that received only rotenone showed non- significant increase in lipid peroxide and non-significant decrease in glutathione peroxidase. It is well known that, the neurotoxin rotenone directly inhibits mitochondrial complex I ${ }^{(29)}$. Mitochondrial complex I inhibition resulted in increased oxidative stress (OS) ${ }^{(29,30)}$ which leads to neuronal cell death.

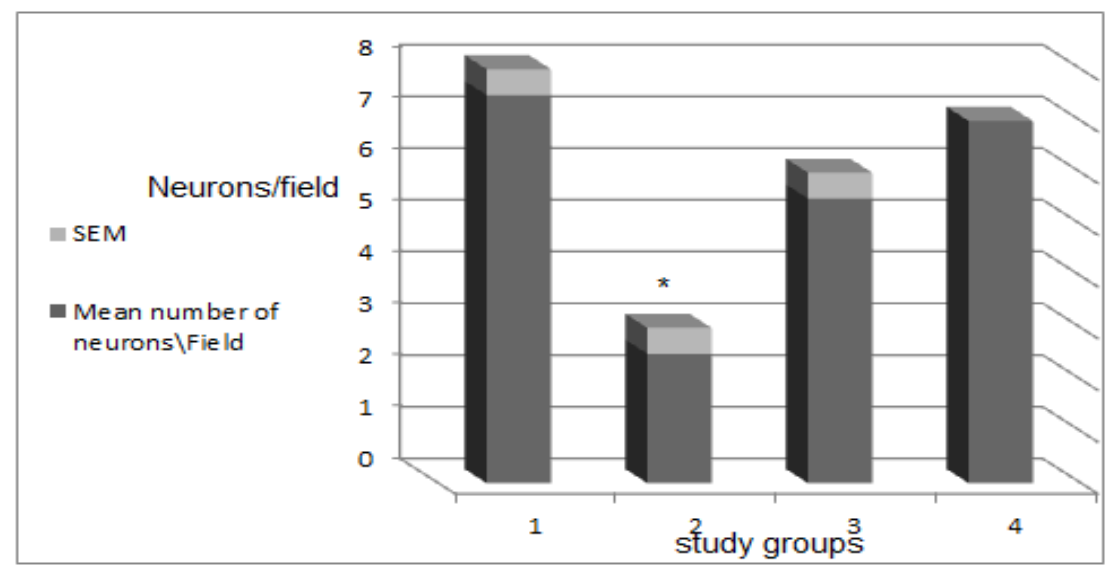

Figure 3: Comparison of the number of neurons in substantia nigra pars compacta in the study groups * significant decrease in the number of neurons in group 2 (rotenone treated) vs. groups 1, 3 and 4 (vehicle-treated, rotenone + intranasal EPO and rotenone + i.p EPO respectively)

However, later studies showed that rotenone effects can be mediated independently of complex I inhibition ${ }^{(31,32)}$. This neurotoxin affects not only the mitochondria function but also microtubule (MT) stability, Ca2+ homeostasis, OS, DNA damage response (DDR), proteasome function, inflammatory response and apoptosis ${ }^{(30,31,}$ 33-43) investigated the toxic effect of rotenone on mouse neuroblastoma cells. They indicated that, intracellular calcium rather than oxidative stress is a major factor for rotenone-induced apoptosis in neuronal cells. In the current study, both intranasal and intraperitoneal rhEPO treatment of the rotenone animals improved the motor deficit but failed to restore the control level and this was confirmed in the histopathological analyses where both intranasal and intraperitoneal rhEPO treatment increased the number of neurons in the
$\mathrm{SNpc}$ in comparison to rotenone group. In agreement with our results; Erythropoietin (EPO) has been shown to be neuroprotective in experimental Parkinson's disease (PD) following direct intra-cerebral injection ${ }^{(44)}$. Similarly, Zhoua et al. ${ }^{(45)}$ demonstrated that, brain penetrating form of EPO is neuroprotective in PD following IV administration. Also, it was found that, in traumatic brain injury intraperitoneally administered EPO improved mitochondrial function and exerted neuroprotective effect $^{(46,47)}$. EPO has been proven to be neuroprotective against mechanisms involved in neuronal death. It has antiinflammatory ${ }^{(48-50)}$, anti-excitotoxic ${ }^{(51)}$, antioxidant $^{(52)}$, and anti-apoptotic ${ }^{(53)}$ effects on neurons and oligodendrocytes ${ }^{(54)}$. It also promotes neurogenesis ${ }^{(55,56)}$, and angiogenesis ${ }^{(57)}$, which are essential for injury repair and normal neurodevelopment. 


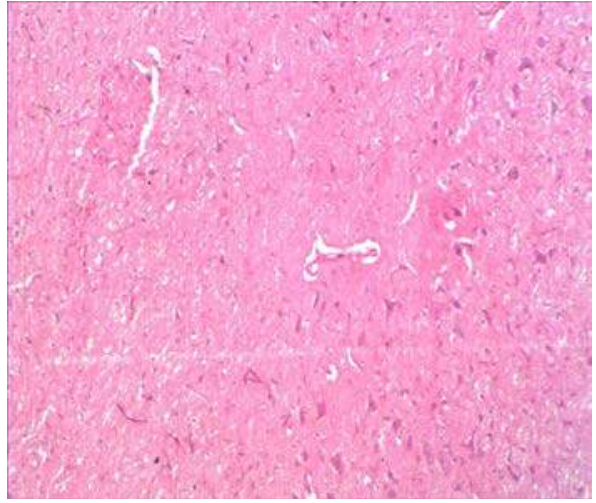

Group 1

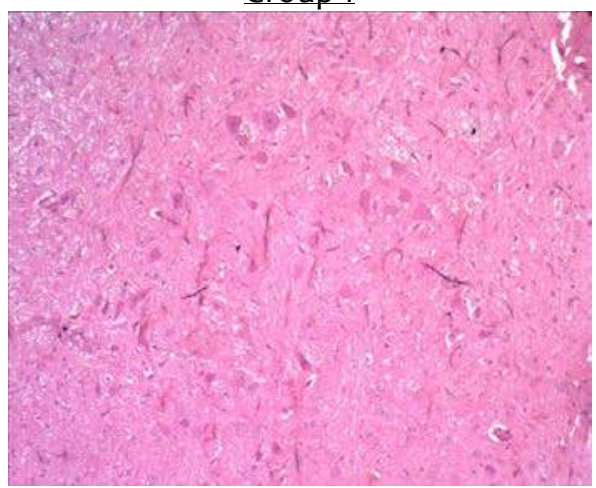

Group 3

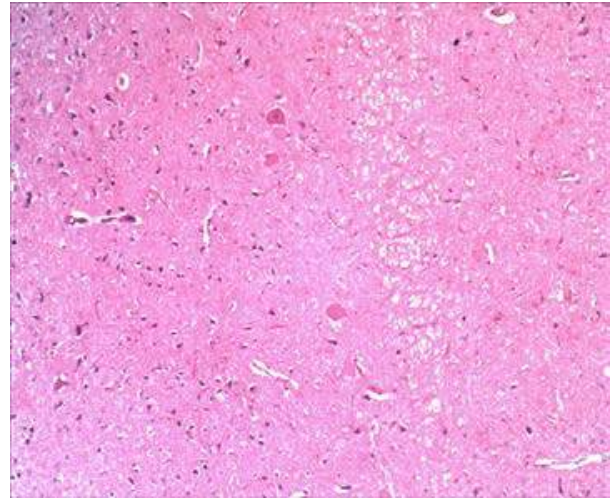

Group 2

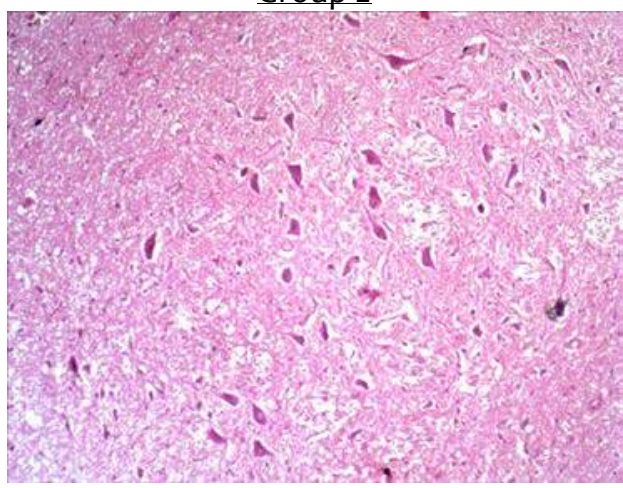

Group 4

Figure 4: Photomicrographs of sections in the substantia nigra of the study groups showing normal nigral neurons (group 1), marked neuronal degeneration with indistinct neuronal boundaries and invisible nuclei in (group 2), and increased number of intact nigral neurons in (groups 3, 4), H\&E x10.

In this study, it was noticeable that, intraperitoneal rhEPO injection of 5000 $\mathrm{u} / \mathrm{kg}$ into rotenone-treated rats was relatively more efficient than intranasal rhEPO delivery of $2.4 \mu$. This finding could be attributed to the low dose of the intranasal rhEPO. Interestingly it was found that, EPO neuroprotection is dose dependent and EPO treatment was found to be ineffective at low dose and at multiple high doses ${ }^{(58)}$. In this study, treatment of rotenone animals with intraperitoneal rhEPO significantly increased lipid peroxide and caused nonsignificant decrease in glutathione peroxidase as compared to controls. This finding could be attributed to the fact that, pharmacologic doses of EPO may show side effects arising from the vascular system such as elevated arterial blood pressure ${ }^{(59,60)}$. In animal models of uremia, it was found that, oxidative stress (OS) contributes to the development of hypertension and to the progression of renal injuries. EPO administration further increases $\mathrm{OS}$, which might partly account for the accentuation of hypertension and renal injury ${ }^{(61)}$. Similarly, it was suggested that in human endothelial cell lines, EPO increased the extracellular and intracellular OS which decreased the activity of dimethylarginine dimethylaminohydrolase $(\mathrm{DDAH})^{(62)}$. DDAH is the enzyme which metabolize asymmetric dimethylarginine (ADMA). ADMA is an endogenous inhibitor of nitric oxide synthase (NOS). In addition, both allantoin, a marker of oxygen free radical generation, and reactive oxygen species increased significantly after EPO treatment compared with control. 

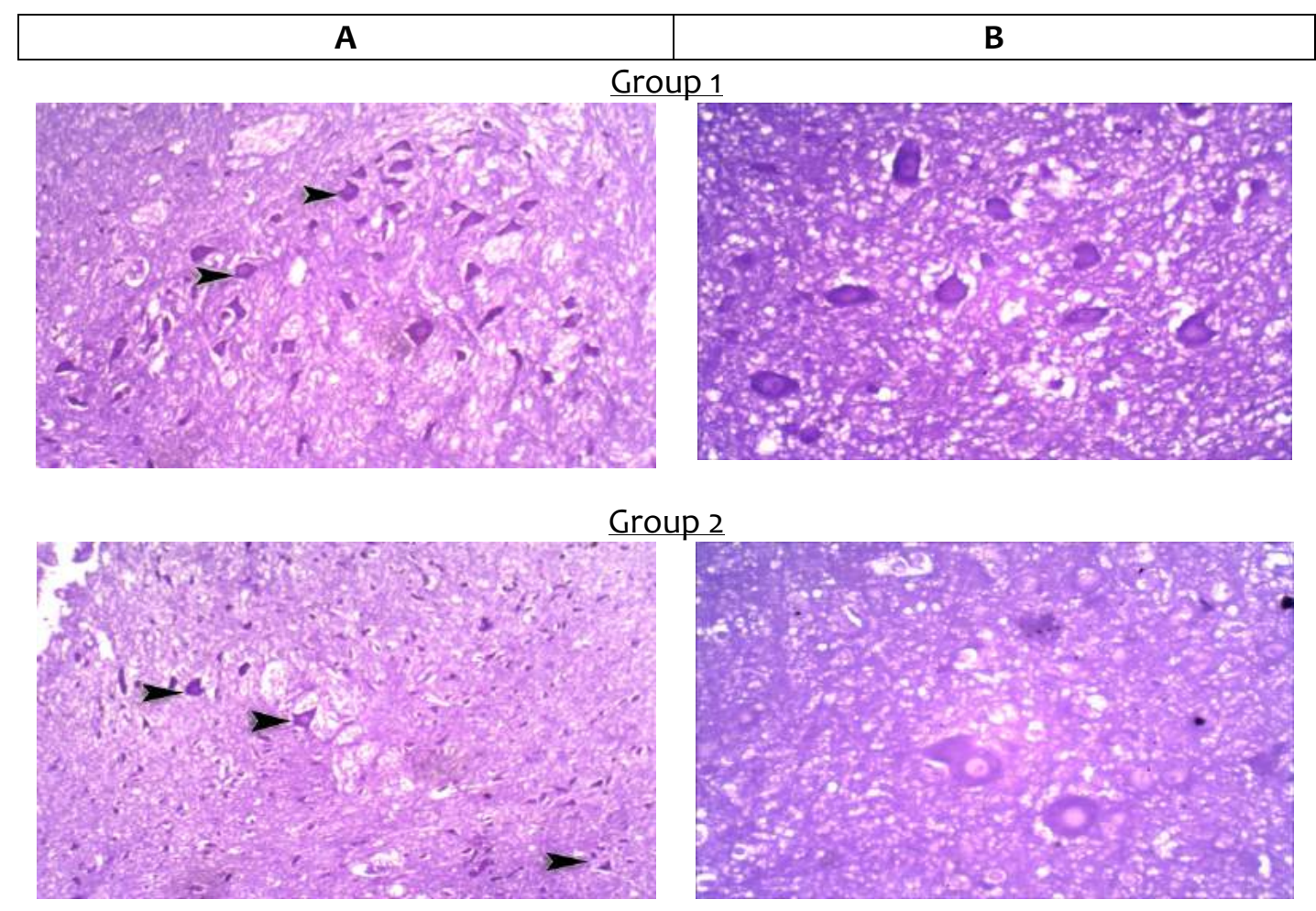

Group 3

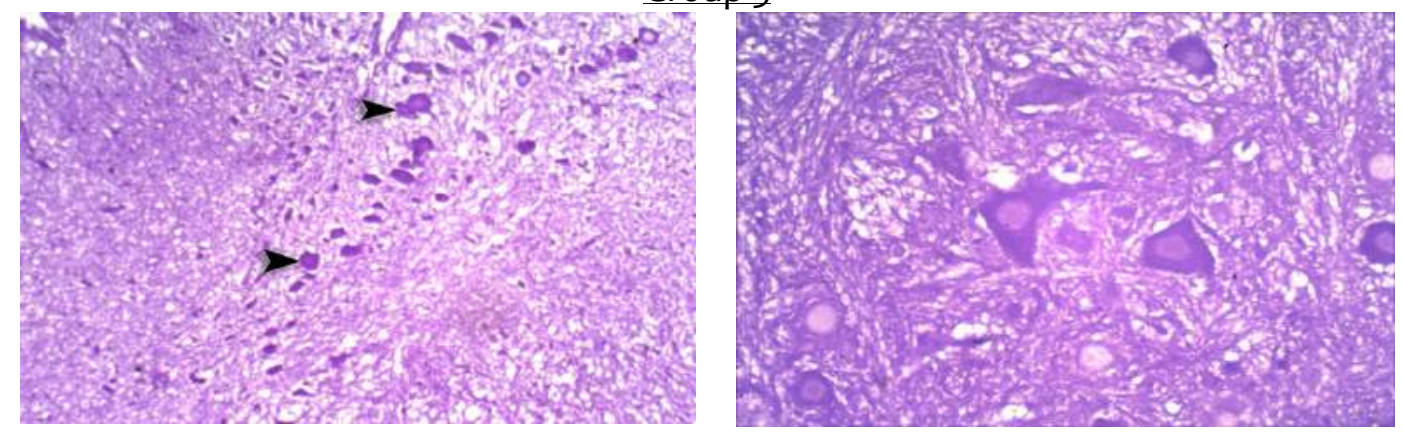

Group 4

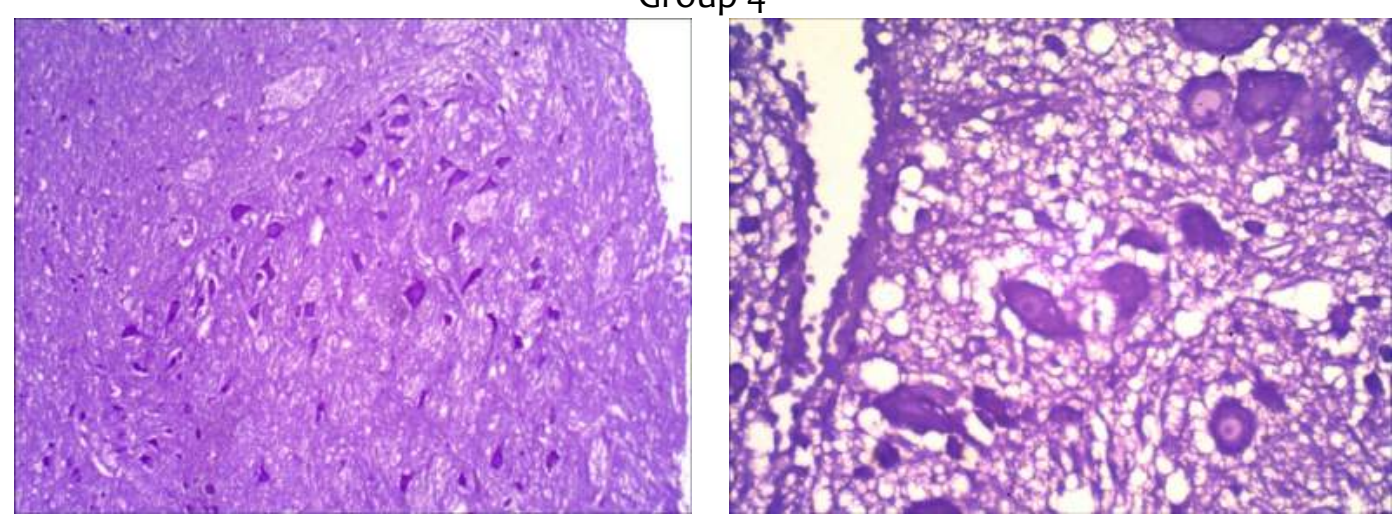

Figure 5: Photomicrographs of sections in the substantia nigra of the study groups showing normal Nissl stained nigral neurons in group 1, marked decrease in Nissl stained nigral neurons in group 2 and increased number of Nissl stained nigral neurons in groups 3 and 4 vs. group 2, (head of arrow: Nissl stained neurons. Cresyl violet Nissl stain (A) ×10 and (B) $\times 40)$. 
Accordingly, in this study, lipid peroxide, a marker of OS, may be increased by rhEPO treatment. Also in the current study, intraperitoneal rhEPO injections significantly increased RBC, $\mathrm{Hb}, \mathrm{HCT}$ and MCV, significantly decreased $\mathrm{MCHC}$ and did not affect $\mathrm{MCH}$. EPO has a known role in erythropoiesis stimulation. It has been shown that, transgenic mice overexpressing systemic EPO developed larger infarcts than wild-type controls, indicating that rhEPO systemic chronic treatment might increase hematocrit and thus deteriorate the afterstroke outcome ${ }^{(63)}$. Since stimulation of erythropoiesis is unwanted for neuroprotection. Therefore, in our study EPO may be unable to produce a significant improvement in the motor deficit because of its adverse effects in the erythropoiesis and OS.

\section{Conclusion}

Our findings suggest that, EPO may have neuroprotective effect in PD. Systemic rhEPO neuroprotective effects may be attenuated by its adverse effects such as increase of OS in the vascular system and stimulation of erythropoiesis. Small doses of intranasal EPO may be sufficient to produce neuroprotection without affecting erythropoiesis and further researches are required to address the mechanisms of neuroprotective effects of EPO.

\section{Acknowledgment}

Authors are very grateful for the generous gift of rhEPO from EPICO Company (Egypt).

\section{References}

1. Lima MM, Andersen ML, Reksidler AB, Vital MA, Tufik $S$. The role of the substantia nigra pars compacta in regulating sleep patterns in rats. Plos ONE 2007, 2(6): e513.

2. Fukui $\mathrm{H}$, Moraes $\mathrm{CT}$. The mitochondrial impairment, oxidative stress and neurodegeneration connection: reality or just an attractive hypothesis? Trends Neurosci 2008;31 (5): 251-256.

3. Sun F, Kanthasamy A, Anantharam V, Kanthasamy AG. Environmental neurotoxic chemicals-induced ubiquitin proteasome system dysfunction in the pathogenesis and progression of Parkinson's disease. Pharmacol Ther 2007; 114 (3): 327-344.

4. Betarbet R, Sherer TB, mackenzie G, Garcia-Osuna M, Panov AV, Greenamyre JT. Chronic systemic pesticide exposure reproduces features of Parkinson's disease. Nat Neurosci. 2000; 3 (12):1301-1306.

5. Madathil KS, Karuppagounder SS, Haobam R, Varghese M, Rajamma $U$, Mohanakumar KP. Nitric oxide synthase inhibitors protect against rotenoneinduced, oxidative Stress mediated parkinsonism in rats. Neurochem Int 2013;6 2 (5): 674-683.

6. Chong ZZ, Lin SH, Kang JQ, Maiese K. Erythropoietin prevents early and late neuronal demise through modulation of Akt1 and induction of caspase 1, 3, and 8 . J Neurosci Res 2003; 71 (5): 659-669.

7. Villa $P$, Bigini $P$, Mennini $T$, Agnello $D$, Laragione T, Cagnotto A, Viviani B, Marinovich $M$, Cerami $A$, Coleman $T$, Brines M, Ghezzi P. Erythropoietin selectively attenuates cytokine production and inflammation in cerebral ischemia by targeting neuronal apoptosis. J Exp Med 2003; 198 (6): 971-975.

8. Shang $Y$, Wu $Y$, Yao S, Wang $X$, Feng $D$, Yang W. Protective effect of erythropoietin against ketamineinduced apoptosis in cultured rat cortical neurons: involvement of PI3K/Akt and GSK-3 beta pathway.Apoptosis 2007: 12 (12): 2187-2195.

9. Kumral A, Gonenc S, Acikgoz O, Sonmez A, Genc K, Yilmaz O, Gokmen N, Duman $\mathrm{N}$, Ozkan H. Erythropoietin increases glutathione peroxidase enzyme activity and decreases lipid peroxidation levels in hypoxic-ischemic brain injury in neonatal rats. Biol Neonate 2005; 87 (1): 15-18.

10. Brines ML, Ghezzi P, Keenan S, Agnello D, de Lanerolle NC, Cerami C, Itri LM, Cerami A. Erythropoietin crosses the blood-brain barrier to protect against 
experimental brain injury. Proc Natl Acad Sci U S A 2000;97 (19): 10526-10531.

11. Campana WM, Li X, Shubayev VI, Angert M, Cai K, Myers RR. Erythropoietin reduces Schwann cell TNF-alpha, Wallerian degeneration and pain-related behaviors after peripheral nerve injury. Eur J Neurosci 2006;23 (3): 617-626.

12. Bernaudin $M$, Bellail A, Marti HH, Yvon A, Vivien D, Duchatelle I, Mackenzie ET, Petit $\mathrm{E}$. Neurons and astrocytes express EPO mRNA: oxygen-sensing mechanisms that involve the redox-state of the brain. Glia 2000; 30 (3): 271-278.

13. Morishita E, Masuda S, Nagao M, Yasuda Y, Sasaki R. Erythropoietin receptor is expressed in rat hippocampal and cerebral cortical neurons, and erythropoietin prevents in vitro glutamate-induced neuronal death. Neuroscience 1997:76 (1): 105-116.

14. Calapai G, Marciano MC, Corica F, Allegra A, Parisi A, Frisina N, Caputi AP, Buemi $M$. Erythropoietin protects against brain ischemic injury by inhibition of nitric oxide formation. Eur J Pharmacol 2000;401 (3): 349-356.

15. Siren $A L$, Fratelli $M$, Brines $M$, Goemans C, Casagrande S, Lewczuk P, Keenan S, Gleiter C, Pasquali C, Capobianco A, Mennini T, Heumann R, Cerami A, Ehrenreich H, Ghezzi P. Erythropoietin prevents neuronal apoptosis after cerebral ischemia and metabolic stress. Proc Natl Acad Sci U S A 2001;98 (7): 40444049.

16. Buemi M, Cavallaro E, Floccari F, Sturiale A, Aloisi C, Trimarchi M, Corica F, Frisina $\mathrm{N}$. The pleiotropic effects of erythropoietin in the central nervous system. J Neuropathol Exp Neurol 2003:62 (3): 228-236.

17. Genc S, Koroglu TF, Genc K. Erythropoietin as a novel neuroprotectant. Restorat Neurol Neurosci 2002; 22 (2): 1-15.

18. Pedroso 11, Bringas ML, Aguiar A, Morales $L$, Alvarez M, Valdés PA, Alvarez $L$. Use of Cuban Recombinant Human Erythropoietin in Parkinson's Disease Treatment. MEDICC Rev. 2012:14 (1): 1117.
19. Jang W, Park J, Shin KJ, Kim JS, Kim JS, Youn J, Cho JW, Oh E, Ahn JY, Oh KW, Kim HT. Safety and efficacy of recombinant human erythropoietin treatment of non-motor symptoms in Parkinson's disease. J Neurol Sci. 2014;337(1-2):47-54.

20. Parraa AL, Rodríguez JC. Nasal Neuro EPO Could be a Reliable Choice for Neuroprotective Stroke Treatment. Cent Nerv Syst Agents Med Chem. 2012; 12 (1): 60-68.

21. Zaitone SA, Abo- Elmatty DM, Elshazly $S M$. Piracetam and vinpocetine ameliorate rotenone induced Parkinsonism in rats. Indian J Pharmacol. 2012; 44(6): 774779.

22. Zhao HW, Lu Y, Li XY, Xu ZH, Zhang ZM, Hu WW, Chen Z. Intranasal administration of low dosage recombinant human erythropoietin inhibits seizure in rat, Zhejiang Da Xue Xue Bao Yi Xue Ban 2009; 38(6):565-571.

23. Correa M, Wisniecki A, Betz A, Dobson DR, O'Neill MF, O'Neill MJ, Salamone JD. The adenosine $\mathrm{A} 2 \mathrm{~A}$ antagonist $\mathrm{KF} 17837$ reverses the locomotor suppression and tremulous jaw movements induced by haloperidol in rats, possible relevance to Parkinsonism. Behav Brain Res. 2004;148 (1-2): 47-54.

24. Janahmadi M, Goudarzi I, Kaffashian MR, Behzadi G, Fathollahi Y, Hajizadeh S. Cotreatment with riluzole, a neuroprotective drug, ameliorates the 3acetylpyridine induced neurotoxicity in cerebellar Purkinje neurones of rats: behavioural and electrophysiological evidence. Neurotoxicology 2009; 30 (3): 393-402.

25. Ohkawa H, Ohishi N, Yagi K. Assay for lipid peroxides in animal tissues by thiobarbituric acid reaction. Anal Biochem. 1979; 95 (2):351-358.

26. Xiong $\mathrm{N}$, Long $X$, Xiong J, Jia $M$, Chen C, Huang J, Ghoorah D, Kong X, Lin Z, Wang T. Mitochondrial complex I inhibitor rotenone-induced toxicity and its potential mechanisms in Parkinson's disease models. Crit Rev Toxicol. 2012; 42(7):613-632. 
27. Morais LH, Lima MM, Martynhak BJ, Santiago R, Takahashi TT, Ariza D, Barbiero JK, Andreatini R, Vital MA. Characterization of motor, depressive-like and neurochemical alterations induced by a shortterm Rotenone administration. Pharmacol Rep. 2012; 64 (5): 1081-1090.

28. Fleming SM, Zhu C, Fernagut PO, Mehta $A$, dicarlo CD, Seaman RL, Chesselet MF.Behavioral and immunohistochemical effects of chronic intravenous and subcutaneous infusions of varying doses of rotenone. Exp Neurol 2004; 187 (2):418429.

29. Sherer TB, Richardson JR, Testa CM, Seo $\mathrm{BB}$, Panov AV, Yagi T, Matsuno-Yagi A, Miller GW, Greenamyre JT. Mechanism of toxicity of pesticides acting at complex I: relevance to environmental etiologies of Parkinson's disease. J Neurochem 2007;100(6):1469-1479.

30. Sherer TB1, Betarbet $R$, Testa $C M$, Seo $\mathrm{BB}$, Richardson JR, Kim JH, Miller GW, Yagi T, Matsuno-Yagi A, Greenamyre JT. Mechanism of toxicity in rotenone models of Parkinson's disease. J Neurosci 2003; 23 (34): 10756-10764.

31. Choi WS, Kruse SE, Palmiter RD, Xia Z. Mitochondrial complex I inhibition is not required for dopaminergic neuron death induced by rotenone, MPP+, or paraquat. Proc Natl Acad Sci USA 2008; 105 (39): 15136-15141.

32. Choi WS, Palmiter RD, Xia Z. Loss of mitochondrial complex I activity potentiates dopamine neuron death induced by microtubule dysfunction in a Parkinson's disease model. J Cell Biol 2011; 192 (5): 873-882.

33. Sherer TB, Trimmer PA, Borland K, Parks JK, Bennett JP Jr, Tuttle JB. Chronic reduction in complex I function alters calcium signaling in $\mathrm{SH}-\mathrm{SY}_{5} \mathrm{Y}$ neuroblastoma cells. Brain Res 2001; 891 (1 - 2): 94-105.

34. Sherer TB1, Betarbet R, Stout AK, Lund $S$, Baptista M, Panov AV, Cookson MR, Greenamyre JT. An in vitro model of Parkinson's disease: linking mitochondrial impairment to altered alpha-synuclein metabolism and oxidative damage. J Neurosci 2002;22 (16): 7006-7015.
35. Kitamura $\mathrm{Y}$, Inden $\mathrm{M}$, Miyamura $\mathrm{A}$, Kakimura J, Taniguchi T. Possible involvement of both mitochondria- and endoplasmic reticulum dependent caspase pathways in rotenone-induced apoptosis in human neuroblastoma $\mathrm{SH}$ SY5Y cells. Neurosci Lett 2002; 333 (1): 25-28.

36. Shamoto-Nagai $M$, Maruyama $W$, Kato $Y$, Isobe K, Tanaka M, Naoi M, Osawa T. An inhibitor of mitochondrial complex I, rotenone, inactivates proteasome by oxidative modification and induces aggregation of oxidized proteins in SHSY5Y cells. J Neurosci Res 2003;74 (4): 589-597.

37. Kweon GR, Marks JD, Krencik R, Leung EH, Schumacker PT, Hyland K, Kang UJ. Distinct mechanisms of neurodegeneration induced by chronic complex I inhibition in dopaminergic and non-dopaminergic cells. J Biol Chem 2004; 279 (50): 51783-51792.

38. Newhouse K, Hsuan SL, Chang SH, Cai B, Wang Y, Xia Z: Rotenone- Induced Apoptosis Is Mediated By P38 And JNK MAP Kinases In Human Dopaminergic SH-SY $5 Y$ Cells. Toxicol Sci 2004;79 (1): 137-146.

39. Ren $Y$, Liu W, Jiang H, Jiang Q, Feng J. Selective vulnerability of Dopaminergic neurons to microtubule depolymerization. J Biol Chem 2005; 280 (40): 34105-34112.

40. Chen MJ1, Yap YW, Choy MS, Koh CH, Seet SJ, Duan W, Whiteman M, Cheung NS. Early induction of calpains in rotenone-mediated neuronal apoptosis. Neurosci Lett 2006;397 (1-2): 69-73.

41. Samantaray S, Knaryan VH, Guyton MK, Matzelle DD, Ray SK, Banik NL. The parkinsonian neurotoxin rotenone activates calpain and caspase-3 leading to motoneuron degeneration in spinal cord of Lewis rats. Neuroscience 2007;146 (2):741-755.

42. Borland MK1, Trimmer PA, Rubinstein JD, Keeney PM, Mohanakumar K, Liu L, Bennett JP Jr. Chronic, low-dose rotenone reproduces Lewy neurites found in early stages of Parkinson's disease, reduces mitochondrial movement and slowly kills differentiated $\mathrm{SH}_{-} \mathrm{SY}_{5} \mathrm{Y}$ neural cells. Mol 
Neurodegener 2008; 3: 21.

43. Swarnkar S, Goswami P, Kamat PK, Gupta S, Patro IK, Singh S, Nath C. Rotenoneinduced apoptosis and role of calcium: a study on Neuro-2a cells. Arch Toxicol. 2012; 86(9):1387- 1397.

44. Xue YQ, Zhao LR, Guo WP, Duan WM. Intrastriatal adminstration of erythropoietin protects dopaminergic neurons and improves neurobehavioral outcome in a rat model of Parkinson's disease. Neuroscience 2007; 146 (3):1245-1258.

45. Zhou QH, Hui EK, Lu JZ, Boado RJ, Pardridge WM. Brain penetrating-lgC erythropoietin fusion protein is neuroprotective following intravenous treatment in Parkinson's disease in the mouse. Brain Res. 2011; 1382: 315-320.

46. Xiong Y, Chopp M, Lee C. Erythropoietin improves brain mitochondrial function in rats after traumatic brain injury. Neurol Res 2009; 31 (5): 496-502.

47. Zhang $\mathrm{Y}$, Xiong $\mathrm{Y}$, Mahmood A, Meng $\mathrm{Y}$, Qu C, Schallert T, Chopp M. Therapeutic effects of erythropoietin on histological and functional outcomes following traumatic brain injury in rats are independent of hematocrit. Brain Res. 2009; 1294, 153-164.

48. Sun Y, Calvert JW, Zhang JH. Neonatal hypoxia/ischemia is associated with decreased inflammatory mediators after erythropoietin administration. Stroke 2005; 36 (8):1672-1678.

49. Juul SE, Beyer RP, Bammler TK, mcpherson RJ, Wilkerson J, Farin FM. Microarray analysis of high-dose recombinant erythropoietin treatment of unilateral brain injury in neonatal mouse hippocampus. Pediatr Res. 2009; 65 (5):485-492.

50. Rees S, Hale N, De Matteo R, Cardamone $L$, Tolcos $M$, Loeliger $M$, Mackintosh A, Shields A, Probyn M, Greenwood D, Harding R.Erythropoietin is neuroprotective in a preterm ovine model of Endotoxininduced brain injury. J Neuropathol Exp Neurol. 2010; 69 (3):306-319.

51. Zacharias R, Schmidt M, Kny J, Sifringer $M$, Bercker $S$, Bittigau $P$, Bührer $C$, Felderhoff-Müser $U$, Kerner T. Dose- dependent effects of erythropoietin in propofol anesthetized neonatal rats. Brain Res. 2010; 1343:14-19.

52. Kumral A, Gonenc S, Acikgoz O, Sonmez A, Genc K, Yilmaz O, Gokmen N, Duman $\mathrm{N}$, Ozkan $\mathrm{H}$. Erythropoietin increases glutathione peroxidase enzyme activity and decreases lipid peroxidation levels in hypoxic-ischemic brain injury in neonatal rats. Biol Neonate 2005; 87 (1):15-18.

53. Kellert BA, Mcpherson RJ, Juul SE. A comparison of high-dose recombinant erythropoietin treatment Regimens in brain-injured neonatal rats, Pediatr Res 2007; 61 (4), 451-455.

54. Iwai $M$, Stetler RA, Xing J, Hu X, Gao $Y$, Zhang W, Chen J, Cao G. Enhanced oligodendrogenesis and recovery of neurological function by erythropoietin after neonatal hypoxic/ischemic brain injury. Stroke 2010; 41 (5):1032-1037.

55. Wang L, Zhang Z, Wang $\mathrm{Y}$, Zhang $\mathrm{R}$, Chopp M. Treatment of stroke with erythropoietin enhances neurogenesis and angiogenesis and improves neurological function in rats. Stroke 2004; 35 (7):1732- 1737.

56. Xiong $\mathrm{Y}$, Mahmood A, Meng $\mathrm{Y}$, Zhang $\mathrm{Y}$, Qu C, Schallert T, Chopp M.: Delayed administration of erythropoietin reducing hippocampal cell loss, enhancing angiogenesis and neurogenesis, and improving functional outcome following traumatic brain injury in rats: comparison of treatment with single and triple dose. J Neurosurg 2010; 113 (3):598-608.

57. Wang L, Chopp M, Gregg SR, Zhang RL, Teng $\mathrm{H}$, Jiang $\mathrm{A}$, Feng $\mathrm{Y}$, Zhang ZG. Neural progenitor cells treated with EPO induce angiogenesis through the production of VEGF. J Cereb Blood Flow Metab. 2008;28(7):1361-1368.

58. Kellert BA, mcpherson RJ, Juul SE. A comparison of high-dose recombinant erythropoietin treatment regimens in brain-injured neonatal rats. Pediatr Res. 2007; 61 (4):451-455.

59. Smith KJ, Bleyer AJ, Little WC, Sane DC. The cardiovascular effects of erythropoietin. Cardiovasc Res 2003; 59(3):538548. 
60. Vaziri ND. Mechanism of erythropoietininduced hypertension. Am J Kidney Dis 1999;33 (5): 821-828.

61. Rancourt ME, Rodrique ME, Aqharazii M, Lariviere $R$, Lebel $M$. Role of oxidative stress in erythropoietin-induced hypertension in uremic rats. Am J Hypertens. 2010;23(3):314- 320.

62. Scalera F, Kielstein JT, MartensLobenhoffer J, Postel SC, Ta"ger $M$, Bode-Böger SM. Erythropoietin Increases
Asymmetric Dimethylarginine in Endothelial Cells: Role of Dimethylarginine Dimethylaminohydrolase. J Am Soc Nephrol 2005;16 (4): 892-898.

63. Wiessner C, Allegrini PR, Ekatodramis D, Jewell UR, Stallmach T, Gassmann M. Increased cerebral infarct volumes in polyglobulic mice overexpressing erythropoietin. J Cereb Blood Flow Metab 2001; 21 (7): 857-864. 